\title{
HUBUNGAN KEBIASAAN MAKAN DENGAN INDEKS MASSA TUBUH PADA MAHASISWI TINGKAT SATU PROGRAM STUDI BIDAN PENDIDIK DI UNIVERSITAS 'AISYIYAH YOGYAKARTA
}

\author{
RELATIONSHIP HABITS WITH BODY MASS INDEX ON STUDENTS LEVEL ONE \\ STUDY PROGRAM BIDAN EDUCATION IN UNIVERSITY 'AISYIYAH \\ YOGYAKARTA
}

\author{
Menik Sri Daryanti \\ Program Studi Bidan Pendidik Universitas 'Aisyiyah Yogyakarta \\ email : meniksridaryanti@gmail.com
}

\begin{abstract}
ABSTRAK
Permasalahan gizi yang seringkali dihadapi oleh remaja adalah permasalahan gizi ganda, yaitu gizi kurang dan gizi lebih. Remaja sering kali mengalami masalah terhadap status gizinya karena dipengaruhi oleh beberapa faktor, salah satunya kebiasaan makan. Prevalensi remaja dengan IMT kurus berkisar antara $30 \%$. Tujuan penelitian ini adalah mengetahui tentang hubungan kebiasaan makan dengan indeks massa tubuh pada mahasiswi tingkat satu Program Studi Bidan Pendidik di Universitas 'Aisyiyah Yogyakarta. Jenis penelitian ini adalah penelitian observasional analitik dengan pendekatan cross sectional. Jumlah sampel 38 mahasiswa dengan teknik pengambilan sampel menggunakan proportional random sampling. Kebiasaan makan diukur menggunakan kuesioner sedangkan indeks massa tubuh diukur menggunakan alat pengukur tinggi badan dan timbangan badan. Analisis data menggunakan korelasi Pearson. Hasil penelitian didapatkan nilai signifikansi 0,835 > 0,05. Ini berarti tidak ada hubungan kebiasaan makan dengan indeks massa tubuh pada mahasiswi tingkat satu Program Studi Bidan Pendidik di Universitas 'Aisyiyah Yogyakarta. Diharapkan mahasiswa lebih memperhatikan konsumsi makanan teutama kandungan gizinya.
\end{abstract}

Kata kunci : kebiasaan makan, indeks massa tubuh

\section{ABSTRACT}

The nutritional problems often encountered by adolescents are multiple nutritional problems, namely less nutrition and more nutrition. Teenagers often have problems with their nutritional status because they are influenced by several factors, one of them is eating habits. The prevalence of adolescents with skinny BMI ranges from $30 \%$. The purpose of this study is to know about the relationship of eating habits with body mass index at the first grade students of the Study Program of Midwife Educators at the University of 'Aisyiyah Yogyakarta. The type of this research is analytic observational research with cross sectional approach. The number of sample is 38 students with sampling technique using proportional random sampling. Feeding habits were measured using a questionnaire while body mass index was measured using height gauges and body 
scales. Data analysis using Pearson correlation. The result of this research is got significance value 0,835>0,05. This means there is no association of eating habits with body mass index in the first grade student of the Study Program of the Midwife Educator at Universitas Aisyiyah Yogyakarta. It is expected that students pay more attention to food consumption especially nutrition content.

Keywords: eating habits, body mass index

\section{PENDAHULUAN}

Masalah gizi merupakan masalah yang paling penting dalam kesehatan masyarakat. Masalah gizi pada anak sekolah menengah pertama merupakan kelompok remaja dan perlu mendapatkan perhatian khusus karena pengaruhnya yang besar terhadap pertumbuhan dan perkembangan tubuh serta dampaknya pada masalah gizi saat dewasa. Bila konsumsi gizi selalu kurang dari kecukupan maka seseorang akan mengalami gizi kurang, sebaliknya jika konsumsi melebihi kecukupan akan menderita gizi lebih dan obesitas (Sulistyoningsih, 2011).

Permasalahan gizi yang seringkali dihadapi oleh remaja adalah permasalahan gizi ganda, yaitu gizi kurang dan gizi lebih. Selain itu, anemia juga menjadi permasalahan lain remaja akibat asupan gizi yang tidak sesuai. Salah satu permasalahan gizi ganda yang disebutkan sebelumnnya yaitu gizi lebih. Gizi lebih merupakan masalah kesehatan pada anak, remaja, dan dewasa di Amerika Serikat. Prevalensi anemia berkisar antara $40 \%$, sedangkan prevalensi remaja dengan IMT kurus berkisar antara 30\% (Hasdianah, 2014).

Remaja sering kali mengalami masalah terhadap status gizinya karena dipengaruhi oleh beberapa faktor, antara lain: penerapan mengenai kebiasaan makan yang buruk tanpa mengetahui zat gizi yang terkandung dalam makanan yang dikonsumsinya, pemahaman gizi yang keliru yang dipicu oleh keinginan remaja memiliki tubuh yang langsing, kesukaan yang berlebihan terhadap sejenis makanan tertentu sehingga kebutuhan akan gizinya tidak dapat terpenuhi dengan baik, promosi produk makanan yang berlebihan melalui media masa dan masuknya produk- produk makanan baru dari luar negri yang kandungan gizinya sangat rendah (Wirjatmadi dan Adriani, 2014).

Kekurangan gizi pada remaja dapat berakibat pada menurunnya daya tahan tubuh sehingga mudah terserang suatu penyakit, pada remaja putri dapat mempengaruhi siklus menstruasi, menghambat masa pembentukan otot pada masa pertumbuhan, kurangnya tingkat intelegensi (kecerdasan) dan produksivitas yang rendah akan mempengaruhi kualitas hidup dimassa dewasa. Sebaliknya kelebihan zat gizi pada seseorang akan membuat seseorang mengalami kelebihan berat badan dan jelas meningkatkan resiko terserang penyakit degenerative seperti diabetes, tekanan darah tinggi dan penyakit jantung (Hasdianah, 2014).

Tujuan penelitian ini adalah Mengetahui tentang hubungan kebiasaan makan dengan indeks massa tubuh pada mahasiswi tingkat 
satu Program Studi Bidan Pendidik Di Universitas 'Aisyiyah Yogyakarta.

\section{METODE PENELITIAN}

Jenis penelitian ini adalah penelitian observasional analitik dengan pendekatan cross sectional. Penelitian akan dilaksanakan di Universitas 'Aisyiyah Yogyakarta.

Dari populasi sejumlah 150 siswi, didapatkan siswi yang akan menjadi sampel penelitian dengan perhitungan $150 \times 25 \%=38$ (dibulatkan dari hasil perhitungan 37,5). Pengambilan sampel menggunakan proportional random sampling.

Pengumpulan data dilakukan dengan cara memberikan lembar kuisioner kebiasaan makan dan mengukur berat badan serta tinggi badan.

Pada penelitian ini untuk menganalisa korelasi antara kebiasaan makan dengan indeks massa tubuh menggunakan uji statistik Pearson Product Moment.

\section{HASIL DAN PEMBAHASAN}

Sebelum data hasil penelitian diolah menggunakan SPSS uji statistik Pearson Product Moment, dilakukan uji normalitas data yang hasilnya semua variabel memiliki nilai signifikansi $>0,05$, sehingga dapat dikatakan bahwa semua data variabel berdistribusi normal.

Setelah data dinyatakan normal, maka dilanjutkan dengan mengolah data hasil penelitian dengan uji statistik Pearson Product Moment dan diperoleh nilai signifikansi $0,835>0,05$. Ini berarti tidak ada hubungan kebiasaan makan dengan indeks massa tubuh pada mahasiswi tingkat satu Program Studi Bidan Pendidik di Universitas 'Aisyiyah Yogyakarta.

Karakteristik pada mahasiswa sebagai responden penelitian adalah sebagai berikut:

Tabel 1 Distribusi Frekuensi Karakteristik Responden Berdasarkan Usia

\begin{tabular}{lcc}
\hline $\begin{array}{l}\text { Usia } \\
\text { (tahun) }\end{array}$ & Frekuensi & $\begin{array}{c}\text { Persentase } \\
(\%)\end{array}$ \\
\hline 17 & 1 & $2,6 \%$ \\
18 & 28 & $73,7 \%$ \\
19 & 9 & $23,7 \%$ \\
Total & 38 & $100 \%$ \\
\hline
\end{tabular}

Sumber: data primer 2017

Berdasarkan Tabel 1

didapatkan data dari 38 responden yang diteliti, paling banyak pada usia responden 18 tahun yaitu sebanyak 28 responden $(73,7 \%)$ dan usia paling sedikit yaitu 17 tahun yaitu 1 responden $(2,6 \%)$.

Tabel 2 Distibusi Frekuensi

Karakteristik Responden

Berdasarkan Tempat Tinggal

\begin{tabular}{|c|c|c|}
\hline $\begin{array}{l}\text { Tempat } \\
\text { tinggal }\end{array}$ & Frekuensi & $\begin{array}{c}\text { Persentase } \\
(\%)\end{array}$ \\
\hline Kos & 30 & $78,9 \%$ \\
\hline Keluarga & 8 & $21,1 \%$ \\
\hline Total & 38 & $100 \%$ \\
\hline
\end{tabular}

menunjukkan bahwa responden yang paling banyak bertempat tinggal di kos sebanyak 30 responden $(78,9 \%)$.

1. Kebiasaan Makan Mahasiswi Tingkat Satu Program Studi Bidan Pendidik Di Universitas

'Aisyiyah Yogyakarta Tabel 3 Distribusi Frekuensi Kebiasaan Makan Mahasiswi Tingkat Satu Program Studi Bidan 


\begin{tabular}{ccc}
\multicolumn{3}{c}{$\begin{array}{c}\text { Pendidik Di Universitas 'Aisyiyah } \\
\text { Yogyakarta }\end{array}$} \\
\hline Skor & Frekuensi & Persentase (\%) \\
\hline 8 & 3 & $7,9 \%$ \\
9 & 5 & $13,2 \%$ \\
10 & 4 & $10,5 \%$ \\
11 & 1 & $2,6 \%$ \\
12 & 4 & $10,5 \%$ \\
13 & 1 & $2,6 \%$ \\
14 & 1 & $2,6 \%$ \\
15 & 5 & $13,2 \%$ \\
16 & 4 & $10,5 \%$ \\
17 & 1 & $2,6 \%$ \\
18 & 8 & $21,1 \%$ \\
19 & 1 & $2,6 \%$ \\
Total & 38 & $100 \%$ \\
\hline
\end{tabular}

Sumber: data primer 2017

Berdasarkan Tabel 3 dapat diketahui dari 38 responden paling banyak mendapat skor kebiasaan makan 18 point sebanyak 8 responden $(21,1 \%)$.

Berdasarkan Tabel 3 dapat diketahui bahwa dari 38 responden, sebanyak 21 responden memiliki skor kebiasaan makan $\geq 13$, dimana ini bisa dikatakan bahwa kebiasaan makan sebagian besar responden adalah baik, karena skor maksimal kebiasaan makan adalah 26. Menurut Arikunto (2013), skor dikatakan baik jika jawaban memiliki skor 56-100\% dan buruk jika jawaban memiliki skor $\leq 55$.

Kebiasaan makan yang buruk, berpangkal pada kebiasaan makan keluarga yang tidak baik sudah tertanam sejak kecil akan terus terjadi pada usia remaja. Mereka makan seadanya tanpa mengetahui kebutuhan akan berbagai zat gizi dan dampak tidak dipenuhinya kebutuhan zat gizi tersebut terhadap kesehatan mereka.
Kebiasaan makan remaja dipengaruhi oleh banyak faktor. Pertumbuhan remaja, meningkatkan partisipasi dalam kehidupan sosial dan aktivitas remaja sehingga dapat menimbulkan dampak terhadap apa yang dimakan remaja tersebut. Remaja mulai dapat membeli dan mempersiapkan makanan untuk mereka sendiri, dan biasanya remaja lebih suka makanan serba instan yang berasal dari luar rumah seperti fast food (Worthington, 2000).

Remaja sebaiknya mengetahui jenis makanan apa yang harus dikonsumsi. Banyak remaja lebih menyukai makanan mengandung tinggi kalori dan rendah vitamin dan mineral. Tentu saja jika hal ini berlanjut akan mengakibatkan kelebihan berat badan. Sulit bagi remaja untuk menubah kebiasaan makan, ara yang bijak adalah bukan dengan diet, tetapi dengan sikap untuk menyeukai dan memilih makanan yang bergizi (Soekirman, 2006).

2. Indeks Massa Tubuh Mahasiswi Tingkat Satu Program Studi Bidan Pendidik Di Universitas 'Aisyiyah Yogyakarta

Tabel 4 Distribusi Frekuensi Indeks Massa Tubuh Mahasiswi Tingkat Satu Program Studi Bidan Pendidik Di Universitas 'Aisyiyah Yogyakarta

\begin{tabular}{ccc}
\hline $\begin{array}{c}\text { Indeks Massa } \\
\text { Tubuh }\end{array}$ & Frekuensi & $\begin{array}{c}\text { Persentase } \\
(\%)\end{array}$ \\
\hline 14 & 1 & $2,6 \%$ \\
15 & 1 & $2,6 \%$ \\
16 & 2 & $5,3 \%$ \\
17 & 5 & $13,2 \%$ \\
\hline
\end{tabular}




\begin{tabular}{ccc}
\hline 18 & 5 & $13,2 \%$ \\
19 & 3 & $7,9 \%$ \\
20 & 2 & $5,3 \%$ \\
21 & 5 & $13,2 \%$ \\
22 & 5 & $13,2 \%$ \\
23 & 3 & $7,9 \%$ \\
25 & 1 & $2,6 \%$ \\
26 & 2 & $5,3 \%$ \\
27 & 1 & $2,6 \%$ \\
30 & 1 & $2,6 \%$ \\
32 & 1 & $2,6 \%$ \\
Total & 38 & $100 \%$ \\
\hline
\end{tabular}

Sumber: data primer 2017

Berdasarkan Tabel 4 dapat diketahui dari 38 responden paling banyak memliki indeks massa tubuh 17, 18, 21 dan 22 sebanyak 5 responden $(13,2 \%)$.

Berdasarkan Tabel 4 dapat diketahui bahwa dari 38 responden, sebanyak 18 responden memiliki indeks massa tubuh $19-24$, sedangkan 14 responden memiliki indeks massa tubuh 14 -18 (di bawah normal) dan 6 responden memiliki indeks massa tubuh 25-32 (di atas normal). Menurut WHO, Batas normal indeks massa tubuh adalah 18,50-24,99.

Jumlah indeks massa tubuh (IMT) dipengaruhi oleh beberapa hal, seperti asupan nutrisi, pola makan, aktivitas fisik, gaya hidup, status sosial-ekonomi, tingkat pendidikan, tingkat pengetahuan, keadaan lingkungan, paparan penyakit kronis dan persentase lemak (Sari, 2012)

Seperti diketahui, berat badan ideal perempuan manula bisa dihitung berdasarkan BMI nya, yaitu perbandingan antara berat dan tingginya. BMI adalah angka yang cukup dapat diandalkan sebagai indikator body fatness untuk sebagian besar orang, meskipun BMI tidak mengukur secara langsung kandungan lemak tubuh. Namun demikian, penelitian-penelitian terdahulu dapat menyimpulkan bahwa BMI berkorelasi se cara langsung dengan lemak tubuh (Mei, 2002).

3. Hubungan Kebiasaan Makan Mahasiswi Dengan Indeks Massa Tubuh Mahasiswi Tingkat Satu Program Studi Bidan Pendidik Di Universitas 'Aisyiyah Yogyakarta

Dari hasil perhitungan korelasi Pearson, diperoleh nilai signifikansi $0,835>0,05$. Ini berarti tidak ada hubungan kebiasaan makan dengan indeks massa tubuh pada mahasiswi tingkat satu Program Studi Bidan Pendidik di Universitas 'Aisyiyah Yogyakarta.

Sebuah penelitian di EuroAmerika dan Afrika Amerika juga menyebutkan bahwa pola makan, khususnya jumlah total makanan yang dikonsumsi berhubungan dengan obesitas pada anak (Nicklas et al, 2003). Selain itu menurut Patro dan Szajewska (2010) obesitas tidak hanya dipengaruhi oleh komposisi makanan yang dikonsumsi, tetapi juga dipengaruhi oleh pola makannya. Mengurangi makan dan frekuensi makanan ringan, membatasi konsumsi minuman manis dan makanan ringan dapat dikaitkan dengan penurunan risiko obesitas.

Menurut WHO, indeks massa tubuh yang $\geq 25,00$ masuk dalam kategori kelebihan berat badan obesitas.

Dari hasil penelitian tidak ada hubungan kebiasaan makan dengan indeks massa tubuh pada mahasiswi tingkat satu Program Studi Bidan Pendidik di Universitas 'Aisyiyah Yogyakarta, karena memang indeks massa tubuh seseorang tidak hanya 
diperngaruhi oleh kebiasaan makan saja, banyak faktor lain yang dapat mempengaruhi indeks massa tubuh seseorang.

Penyakit yang telah lama diderita seseorang (kronis) juga dapat mempengaruhi kondisi fisik dan pola makannya sehingga dapat mempengaruhi IMT, contohnya seseorang yang sudah lama menderita kanker ataupun penyakit infeksi yang lama seperti tuberkulosis akan mengalami penurunan berat badan secara drastis (Speroff, 2010)

Tingginya status sosial-ekonomi juga dapat meningkatkan daya beli seseorang untuk memenuhi kebutuhan nutrisinya. Tingkat pendidikan, pengetahuan dan tingkat sosial ekonomi juga dapat mempengaruhi gaya hidup dan aktivitas seseorang sehari-hari dan akhirnya mempengaruhi IMT (Nazaria, 2012).

Hasil penelitian ini mendukung dari penelitian Elisabeth (2015) yang didapatkan bahwa tidak ada hubungan frekuensi makan dengan $\operatorname{IMT}(\mathrm{p}=0,109)$.

\section{SIMPULAN}

Tidak ada hubungan kebiasaan makan dengan indeks massa tubuh pada mahasiswi tingkat satu Program Studi Bidan Pendidik di Universitas 'Aisyiyah Yogyakarta, nilai signifikansi 0,835 $>0,05$.

Diharapkan mahasiswa lebih memperhatikan konsumsi makanan teutama kandungan gizinya.

\section{DAFTAR PUSTAKA}

Adriani, M. 2015. Peranan Gizi dalam Siklus Kehidupan.
Jakarta: Kencana Prena Media Group.

Hasdianah, et.al,. 2014. Gizi pemanfaatan gizi, diet dan obesitas. Yogyakarta: Nuha Medika.

Mei Z, Grummer-Strawn LM, Pietrobelli A, Goulding A, Goran MI, Dietz WH. Validity of body mass index compared with other body -composition screening indexes for the assessment of body fatness in children and adolescents. American Journal of Clinical Nutrition 2002;7597-985.

Nazaria S. 2012. Hubungan pendapatan keluarga, usia menarche ibu dan tingkat stres siswi dengan status menarche siswi kelas VII dan VIII SLTP Al-Azhar 2 Pejaten dan SLTPN 175 Jakarta Selatan tahun 2011.Skripsi. Universitas Andalas.

Nicklas, TA. Yang, SJ. Baranowski, T. Berenson, G. 2003. Eating patterns and obesity in children. The Bogalusa Heart Study. Am $J$ Prev Med. 25(1):9-16.

Patro, B and Szajewska, H. 2010. Meal patterns and childhood obesity. Curr Opin Clin Nutr Metab Care. 13(3):300-4.

Sari, RI. 2012. Faktor yang berhubungan dengan status gizi remaja usia 12-15 tahun di Indonesia tahun 2007 (analisis data sekunder Riskesdas tahun 2007). Skripsi. Jakarta: Fakultas Kesehatan Masyarakat Universitas Indonesia.

Soekirman. 2006. Hidup Sehat Gizi Seimbang Dalam Siklus 
Kehidupan

Manusia.

Primamedia Pustaka: Jakarta.

Speroff L, Marc AF. 2010. Clinical

endocrinology and fertility.

Edisi ke-8. Philadelphia:

Lippincott Williams \&

Wilkins.

Sulistyoningsih, H. 2011. Gizi untuk kesehatan ibu dan anak. Graha ilmu. Yogyakarta.

Worthington. 2000. Nutrition Troughout The Life Cycle. The MaGraw-Hill International Edition: USA. 